\title{
Variabilidad en el síndrome de ventrículo derecho hipoplásico. Estenosis pulmonar crítica y fístula coronaria: reporte de caso
}

\author{
Hypoplastic right ventricle syndrome variability. Critical pulmonary stenosis and coronary \\ fistula: case report
}

\author{
María E. Sandoval-Sandoval ${ }^{1}$, Laura R. Chávez-Priego ${ }^{1}$, José A. García-Montes ${ }^{2}$ y \\ Clara A. Vázquez-Antona ${ }^{1 *}$ \\ ${ }^{1}$ Servicio de Ecocardiografía Pediátrica; ${ }^{2}$ Servicio de Hemodinámica Pediátrica. Instituto Nacional de Cardiología Ignacio Chávez, Ciudad de México, \\ México
}

El espectro del ventrículo derecho hipoplásico es amplio y desafiante, ya que dependiendo de su variabilidad anatómica y funcionalidad se planteará qué tratamiento es el adecuado.

Presentamos el caso de un lactante de sexo femenino, de 15 meses de edad, quien cursó asintomática, valorada en consulta de seguimiento por cianosis con saturación de oxígeno del 70\%, motivo por el cual es referida a nuestra institución. El ecocardiograma transtorácico mostró hipoplasia importante tanto de la válvula tricúspide $(Z-3.49)$ como pulmonar $(Z-7.43)$, con un ventrículo derecho dilatado (DDVD $Z+3.08$ ); en la imagen $4 \mathrm{C}$ con Doppler se observó flujo sístolo-diastólico en la pared lateral de anillo tricuspídeo que desembocaba en el ventrículo derecho y dilatación de la coronaria derecha $(Z+7.8)$, sugestivo de fístula coronaria (Fig. 1), y estenosis pulmonar crítica, predominantemente valvular, con un gradiente máximo de $122 \mathrm{mmHg}$ (Fig. 1). Se realizó cateterismo cardiaco para colocación de stent en el tracto de salida del ventrículo derecho, quedando con un gradiente de $43 \mathrm{mmHg}$, y cierre de la fístula coronaria, la cual fue fallida por el tamaño de la fístula (Fig. 2).

La finalidad de presentar este caso es mostrar el amplio espectro de presentación del síndrome del ventrículo derecho hipoplásico, ahora con dos asociaciones poco frecuentes como son la dilatación del ventrículo derecho en presencia de hipoplasia de las válvulas tricúspide y pulmonar con estenosis pulmonar crítica y fístula coronaria derecha. Suponemos que esta asociación no es por azar y que tiene un factor predisponente de acuerdo con las bases embrionarias de la cardiopatía y otro desencadenante que depende de la fisiopatología que presenta ${ }^{1}$.

Para llamar hipoplásico a un ventrículo, este debe tener una constitución tripartita, con porción de entrada, trabecular y salida, pero al menos dos de ellas se encuentran hipodesarrolladas ${ }^{2}$; generalmente cursa con atresia de la válvula pulmonar y en un menor número de casos con estenosis. Se ha reportado que el tamaño del anillo tricuspídeo se relaciona con las dimensiones del ventrículo derecho ${ }^{2}$, lo que no se observa en el caso que presentamos. En relación con la asociación de fistula coronaria derecha, consideramos que la presencia de hipoplasia tricuspídea y pulmonar con estenosis crítica favoreció las uniones entre la red vascular subepicárdica primitiva y los sinusoides intramiocárdicos, que en condiciones normales no entran en contacto, ya que cuando se completa el proceso de vasculogénesis se produce la compactación del miocardio, con la desaparición de los sinusoides primitivos y la aparición de la

\section{Correspondencia:}

*Clara A. Vázquez-Antona

E-mail: vazquezantona@gmail.com
Disponible en internet: 15-10-2020 Arch Cardiol Mex. 2021;91(2):267-268 www.archivoscardiologia.com CC BY-NC-ND (http://creativecommons.org/licenses/by-nc-nd/4.0/). 


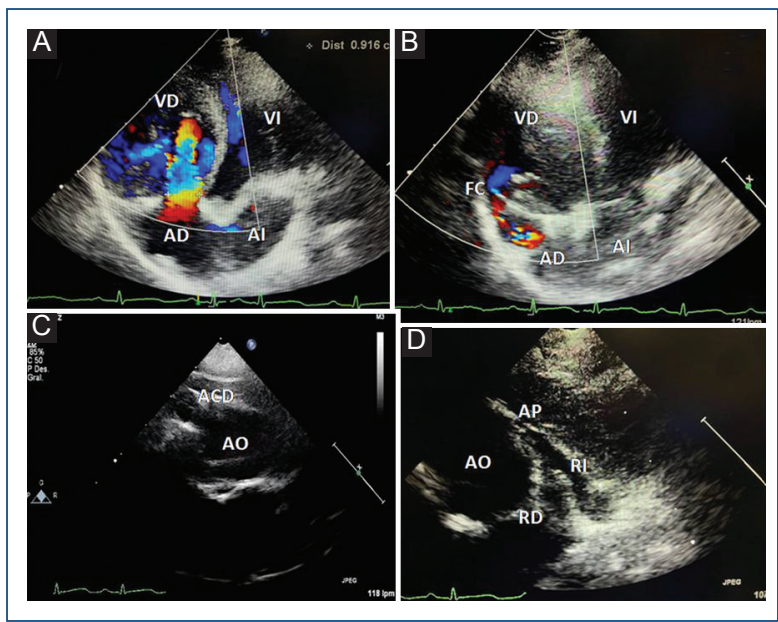

Figura 1. Imágenes ecocardiográficas transtorácicas. A: vista apical 4C en color que muestra hipoplasia del anillo tricuspídeo y dilatación del ventrículo derecho. B: visión apical $4 C$ en color con angulación posterior que muestra flujo anormal lateral al anillo tricuspídeo al ventrículo derecho de la fístula coronaria (Vídeo 1). C: visión en el eje corto paraesternal que muestra la aorta al centro y el origen de la coronaria derecha dilatada. D: visión en el eje corto paraesternal que muestra hipoplasia de la arteria pulmonar y las ramas pulmonares que son confluentes, con estenosis en su origen. ACD: coronaria derecha; $A D$ : atrio derecho; $A$ : atrio izquierdo; $A 0$ : aorta; $\mathrm{AP}$ : arteria pulmonar; $\mathrm{FC}$ : fístula coronaria; $\mathrm{RD}$ : rama derecha de la arteria pulmonar; RI: rama izquierda de la arteria pulmonar; VD: ventrículo derecho; VI: ventrículo izquierdo.

circulación coronaria. Hasta donde sabemos, la aparición y la prevalencia de fístulas de las arterias coronarias en pacientes con estenosis pulmonar es poco frecuente ${ }^{3}$. Aggarwal, et al. ${ }^{4}$ reportaron una incidencia del $14 \%$ de fístulas coronarias en recién nacidos con estenosis pulmonar crítica, asociándolo a anillos tricuspídeos pequeños y menor desarrollo de la cavidad ventricular y la válvula pulmonar, la mayoría de estos casos con fístulas pequeñas.

En cuanto a la dilatación del ventrículo derecho que presenta esta paciente, creemos que puede ser secundaria a la sobrecarga de volumen por el cortocircuito arteriovenoso que produce la fístula y que, a pesar de tener un ventrículo aparentemente desarrollado, las anormalidades de la arquitectura miocárdica ventricular derecha persisten, lo que aunado a la hipoplasia tricuspídea impide una corrección biventricular.

\section{Financiamiento}

Ninguno.

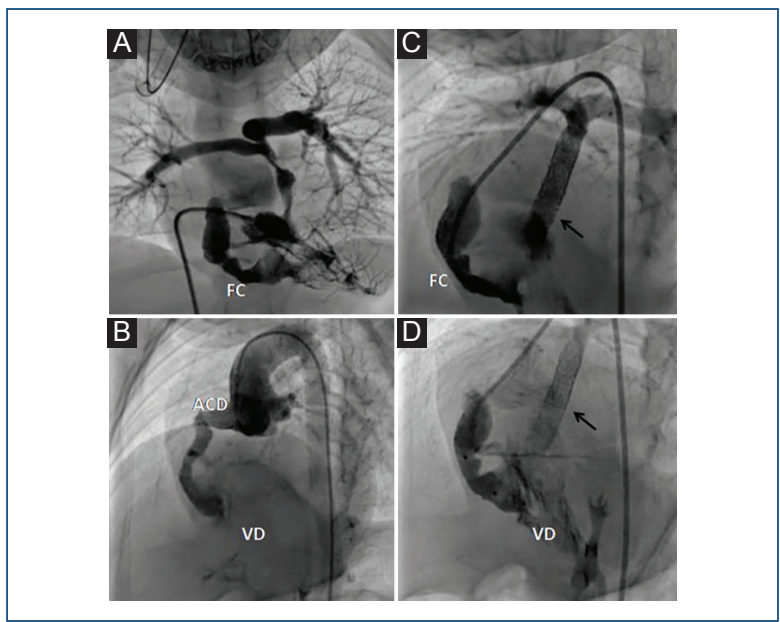

Figura 2. Imágenes angiográficas. A: ventriculografía derecha en proyección anteroposterior con craneal en la que se observa estenosis pulmonar grave con hipoplasia de anillo valvular y TAP, con ligera estenosis en el origen de las ramas y por contraflujo el llenado de la fistula coronaria, con la coronaria derecha ectásica, tortuosa, y con zonas aneurismáticas, lo que se corrobora en las siguientes imágenes. B: aortografía en proyección axial izquierda. C: con el paso del catéter hacia la fístula, se observa el stent en la vía de salida del ventrículo derecho y la arteria pulmonar (flecha). D: colocación de un dispositivo tipo Vascular Plug II para el cierre de la fístula, aún con leve cortocircuito hacia el ventrículo derecho. ACD: arteria coronaria derecha; FC: fístula coronaria; TAP: Tronco de arteria pulmonar; VD: ventrículo derecho.

\section{Conflictos de intereses}

Ninguno.

\section{Responsabilidades éticas}

Protección de personas y animales. Los autores declaran que para esta investigación no se han realizado experimentos en seres humanos ni en animales.

Confidencialidad de los datos. Los autores declaran que en este artículo no aparecen datos de pacientes.

Derecho a la privacidad y consentimiento informado. Los autores declaran que en este artículo no aparecen datos de pacientes.

\section{Bibliografía}

1. Rangel A, Muñoz L, Solorio S. Fístulas arteriovenosas coronarias múltiples. ¿Azar o predeterminación? Arch Cardiol Mex. 2003;73:31-7.

2. Muñoz L, Galindo M, Kuri M, Epinola N. Hipoplasia ventricular derecha. Estudio morfométrico y morfológico. Arch Cardiol Mex. 2007:77:181-93.

3. Verdini D, Vargas D, Kuo A, Ghoshhajra B, Kim P, Murillo H, et al. Coronary-pulmonary artery fistulas: a systematic review. J Thorac Imaging. 2016;31:380-90.

4. Aggarwal V, Mulukutla V, Maskatia S, Justino $\mathrm{H}$, Mullins C, Qureshi A Outcomes after balloon pulmonary valvuloplasty for critical pulmonary stenosis and incidence of coronary artery fistulas. Am J Cardiol. 2018;121:1617-23. 